\title{
To the Point: Integrating the Obstetrics and Gynecology Core Clerkship into a Longitudinal Integrated Curriculum in US Medical Schools
}

\author{
Archana Pradhan ${ }^{1}$ (D) Susan Bliss ${ }^{2} \cdot$ Samantha Buery-Joyner $^{3} \cdot$ LaTasha Craig $^{4} \cdot$ Elise Everett $^{5}$ - David Forstein ${ }^{6}$.

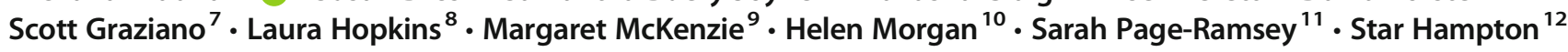

Accepted: 1 October 2020 / Published online: 14 October 2020

(C) International Association of Medical Science Educators 2020

\begin{abstract}
This article, from the "To the Point" series that is prepared by the Association of Professors of Gynecology and Obstetrics (APGO) Undergraduate Medical Education Committee, is a review of issues to consider when integrating obstetrics and gynecology into a Longitudinal Integrated Clerkship (LIC) model. The background, objectives, and outcomes related to LIC are discussed. Specific challenges and solutions for structuring an LIC in the context of obstetrics and gynecology are examined, which include student/faculty issues as well as process matters such as general infrastructure and specific curriculum concerns.
\end{abstract}

Keywords Longitudinal integrated clerkships $\cdot$ Medical education $\cdot$ Curriculum

\section{Background}

The origins of the LIC are rooted in the Rural Physician Associate Program (RPAR) at the University of Minnesota in the 1970s as a means to address rural physician workforce shortage [1]. Despite the success of RPAR, it was not until the 1990s that a handful of medical schools attempted to replicate the LIC model. The LIC curriculum replaces a medical student's traditional core specialty-based clerkships with an integrated

Archana Pradhan

archana.pradhan.md@rutgers.edu

1 Department of Obstetrics, Gynecology, and Reproductive Sciences, Rutgers Robert Wood Johnson Medical School, New Brunswick, NJ, USA

2 Obstetrics and Gynecology, Carolinas Medical Center, Charlotte, NC, USA

3 Department of Obstetrics and Gynecology, Virginia Commonwealth University INOVA Campus, Fairvax, VA, USA

4 Department of Obstetrics and Gynecology, Oklahoma University College of Medicine, Oklahoma City, OK, USA

5 Department of Obstetrics, Gynecology, and Reproductive Sciences, Larner College of Medicine at University of Vermont, Burlington, VT, USA clerkship model. LIC students are exposed to multiple specialties simultaneously. All LIC models have three basic tenets: (1) students need to be exposed to all core clinical training issues to which clerks on the traditional clerkship model are exposed, (2) students should participate in the comprehensive care of patients over time and (3) clinical clerks ought to develop mentoring relationships with these patients' clinicians [2]. The Carnegie Foundation report in 2010 recommended students have more integration in content, a better mechanism for
6 Department of Obstetrics and Gynecology, Touro College of Osteopathic Medicine-Harlem, Manhattan, NY, USA

7 Department of Obstetrics and Gynecology, Loyola School of Medicine, Chicago, IL, USA

8 Department of Obstetrics and Gynecology, Ottawa University, Ottawa, Canada

9 Department of Obstetrics and Gynecology, Cleveland Clinic Lerner College of Medicine, University of Michigan School of Medicine, Cleveland, OH, USA

10 Department of Obstetrics and Gynecology, University of Michigan School of Medicine, Ann Arbor, MI, USA

11 Department of Obstetrics and Gynecology, UT Health San Antonio, San Antonio, TX, USA

12 Department of Obstetrics and Gynecology, Warren Alpert Medical School of Brown University, Providence, RI, USA 
professional identity formation, and means to foster scientific inquiry and individualized learning. LICs can offer many of these opportunities [3].

Now that early adopter schools have produced $40+$ cumulative years of positive outcomes data, many medical schools across the USA are attempting to implement the LIC curriculum as a possible solution to address the national shortage of primary care physicians, to enhance patient-physician communication and continuity, to improve academic results, and to develop more meaningful relationships and feedback with faculty mentors and patients $[4,5]$. For many of us, participation in the LIC curriculum as obstetrics and gynecology educators is not optional and can be a challenge to implement. The fast-paced nature of the specialty and varied faculty staffing models can make continuity of care and continuity of student-faculty interactions difficult to schedule. However, it is important to keep in mind that the implementation of the LIC curriculum may be a strategy to increase the number of students choosing obstetrics and gynecology as a specialty [6]. Additionally, it gives us the opportunity to appropriately train primary care physicians in basic women's health issues.

\section{Outcomes}

Many outcome studies have evaluated LIC programs with regard to academic performance [7]. Academic results (as measured by summative student assessments) of students on LIC tracks were better or equivalent to students on traditional clerkship tracks. Academic results that were evaluated were summative student assessments such as institution developed subject examinations, National Board of Medical Examination (NBME) subject scores, and United States Medical Licensing Examination (USMLE) performance [8]. For example, a comparison of ob-gyn mean NBME scores between students at the Yankton 12-month integrated longitudinal program compared with students from traditional obgyn clerkships at the University of South Dakota showed no significant difference. Additionally, the students in the integrated program also had better long-term learning retention [9]. Similarly, students on the traditional ob-gyn clerkship at the University of North Dakota had an average NBME score of 73.9, while their LIC counterparts had an average score of 74.8 [10].

Few studies have drilled down and compared other parameters specific to the obstetrics and gynecology clinical clerks on the LIC track versus the traditional clerkship track. A study which compared student experience on the traditional obstetrics and gynecology clerkship with single supervisor/ elimination of fragmented activities experience showed that students on the revised experience performed twice the amount of obstetric procedures and a significantly enhance student-faculty relationship [11]. A study out of the University of Hawaii that tracked LIC students versus traditional block students confirmed that students on the LIC obgyn clerkship logged in more clinical experiences than traditional block ob-gyn clerkship students [12].

Many studies have examined overall clinical performances, learner experiences, career choices, clinical supervision, and patient perception between all students on the two tracks. Objective Standardized Clinical Examination (OSCE) scores as a proxy for clinical performance showed that LIC curriculum students scored higher than traditional track students [13]. LIC students report improved learner experiences in several different ways. "Students report having increased patientcentered skills including better developed clinical communication skills, and demonstrate a deeper understanding of the psycho-social component of the biopsychosocial model.'[8]. Preceptors note a high level of student productivity as the LIC experience progresses [14, 15]. Clinical supervision outcomes from the LIC faculty perspective are extremely positive [16]. At UCSF, with regard to clinical supervision from the student viewpoint, LIC students rated clerkship experiences with regard to faculty observation, faculty teaching, feedback, and clerkship overall higher than their traditional clerkship counterparts [17]. Faculty familiarity with students allows educators to tailor their teaching to an individual student's needs. Additionally, LIC students report increased confidence in their clinical skills and feel that they are better prepared for internship [18, 19]. Importantly, these benefits of an LIC education are reported to endure through residency and into practice [20]. As far as career choice is concerned, students in the LIC track are more likely to ob-gyn as a specialty than students in the traditional track [21]. Furthermore, patients who were taken care of by LIC students valued continuity relationships with students much as they valued continuity relationships with providers $[22,23]$. The overwhelmingly positive outcomes data has led to the call for the development of LIC curricula at medical schools across the country.

\section{Implementation Considerations}

In order to implement an LIC program successfully, several issues need to be considered prior to committing to develop this type of curriculum. Many of the lessons learned are from colleagues in other specialties who have led LIC curriculum implementation across the world. These topics can be categorized as student/faculty issues, general infrastructure logistics, and specific curriculum concerns. If these issues are not addressed from the outset, it is highly unlikely that a medical school can sustain an LIC track.

Choosing the correct students and providing appropriate support to students in the LIC cohort is critical [24]. LIC students must be able to adapt through quick changes and be 
resilient through times of confusion en route to developing professional competence and confidence [25]. Students who are enrolled in the LIC track may experience initial anxiety at the prospect of learning core material in multiple disciplines simultaneously. LIC students do not receive final formal assessments until the end of the year and this too can make students question whether they are acquiring the core knowledge required of a junior clinical clerk. LIC students also need to be self-directed learners as they are given the freedom to follow individual patients to various specialty visits and procedures. An appropriate selection process that seeks out mature learners who have expressed a sincere interest in pursuing a career in a primary care specialty is a key component of developing a successful LIC program [17, 26].

Similarly, identifying faculty members who have "bought in" to the goals of the LIC is important to the success of this non-traditional curriculum [27]. Some medical schools may have faculty who are resistant to change such as a new curriculum, and thus will need support from many levels, including the Dean's office and administration [28]. The traditional immersive curriculum is how most physicians were trained. Transitioning to a new model requires education for educators and administrators and an understanding of the benefits and challenges of the longitudinal curriculum [29]. Preceptors initially may need increased faculty development to understand how to deliver the same content in this new format. An innovative study texted brief faculty development podcasts to community-based LIC preceptors; 70\% reported that the intervention affected their teaching style and they were likely to listen to future podcasts [30]. As LIC students are learning about several core specialties simultaneously, preceptors need faculty development on how to monitor and ensure that these students develop and retain specialty-specific skill sets. Faculty development focused on teaching around continuity, connection, communication, coaching, commitment, care, and community has been identified as a practical framework for LIC preceptors [31]. A UNC-Asheville study interviewed 4 cohorts of LIC students and developed the following 7 themes to develop teaching tips for faculty: enhance teaching; create bring-backs (learning topics to bring back to preceptors); support patient ownership; structure clinic; improve feedback; engage learners; and develop a relationship [32].

Implementation of an LIC curriculum also needs to account for impact on faculty preceptors. Budget to attract and compensate these preceptors should be established [17]. Serving as an LIC clerkship site is a rewarding experience; however, preceptors have reported seeing $1-3$ patients less per session or starting patient hours earlier to accommodate for the increased time required to teach [33]. Because of the one-onone teaching aspect of an LIC, concerns that it may be more costly to implement have arisen. Hudson and colleagues found that students can be cost-neutral or even favorable to an office if the student is there for at least two months, since the student becomes an integral member of the team [34]. Faculty do report a high level of satisfaction with the student-preceptor relationship [14, 15]. Additionally, a study of faculty and nurses who participated as LIC preceptors reported increased reflective practice, improved value of professional identity, and increased enthusiasm for interprofessional learning [35].

Creating an infrastructure that can support the learners and the teachers is a critical element in the development of an LIC. Community settings provide more opportunities for LIC students to engage in patient care activities [36]. In addition, community settings may allow part-time physicians to have a more active role in medical student education, especially if the student is only with them a half-day per week. When implemented in a tertiary care setting, students may be placed in specialty or subspecialty clinics which may not afford the students the opportunity to experience the common patient conditions. It is important to have built in time where students can have the flexibility to enrich their patient encounters and schedule clinical experiences which they may not have previously seen. For example, a student may have a patient with fibroids who is being scheduled for a uterine artery embolization in radiology. The student's ability to observe the patient's procedure will enhance the learning. Because of the varied schedule, it may take students longer to "get in the flow"; however, once they do, their experiences become more solidified with long-lasting results. LICs have been successfully implemented in both rural and urban settings [37]. In any setting, it is important that the clinical site (and its administrative support team) is aligned with the mission of the medical school, while having the financial support to host a medical student.

Scheduling the varied aspects of an LIC can be complicated. Each student may have a different weekly schedule, which needs to be juggled. Having support staff who understand these complexities is invaluable in maintaining and adjusting schedules as needed. They can also keep track of preceptors' availability, and how many preceptors are needed in each specialty at any time. Some challenges which were reported [38] in the initial pilot year included underestimating time requirements, finalizing the details of the model (\# of preceptors, scheduling weekly activities), and the transition from one process to the next. The leadership team needs to be able to adapt and be flexible, in the initial phase. There have not been any studies looking at the optimal schedule to learn the ob-gyn material; thus, there is room for adapting the schedule to optimize the strengths at an individual institution. For example, some programs have ob-gyn purely as a longitudinal experience, while others have it mixed with an inpatient block rotation. The scheduling structure can be variable based on whether a medical school has LIC learners and traditional learners at the same site or a completely different location. This is dependent on an institution's curriculum objectives, as well as 
faculty/affiliation resources, i.e., does a particular regional site have all the core specialties represented?

LIC learners are immersed in clinical experiences during the clerkship phase of an individual medical school's curriculum, so these students are usually second or third year medical students. Scheduling educational sessions throughout the preclerkship and clerkship years will permit LIC students to (1) develop a community within the students on the LIC track and (2) delve into educational cases which they have not yet experienced. Interdisciplinary simulations between obstetrics and pediatrics can efficiently address requirements in multiple fields and promote deep learning [39]. For students who are placed in the LIC track, encouraging and monitoring the educational process can be quite intensive. Students want and need regular feedback, and this can be provided on a regular basis with the continuity of preceptors who will observe a student's growth over time. Periodic (perhaps quarterly) feedback to assess the student's overall performance including patient care, medical knowledge, professionalism, lifelong learning, systems-based practice, and communication skills should be provided [40].

Documenting comparability between clerkship sites within a medical school is critical for LCME accreditation [28]. An important element of this is making the goals and objectives clear, and thus, the experiences expected are transparent. Frequent monitoring of students' experiences allows for early intervention to assure that they are achieving the required experiences in their longitudinal curriculum. With more electronic tracking resources available, this can be achieved and monitored with a central system. Ideally, students can log their clinical experiences and faculty can review them regularly. An electronic system in which the students can view their progress and evaluations in a timely fashion could facilitate prompt feedback with correction of errors. The use of tablets can also support a student's individual learning style and help the student be a self-regulated learner [41]. It is important to keep in mind that students on the traditional or LIC ob-gyn clerkship are not required to have the exact same opportunities - but they do have to have comparable experiences. APGO has a plethora of resources such as medical student objectives, a curriculum building tool, and a logbook which can be used to ensure that students on LIC and traditional track receive comparable educational experiences [42].

Student assessment should be based on the same goals and objectives as in a traditional-based curriculum. Since there may be fewer individual evaluators for any one student, preceptor development is important to ensure objective evaluation. Utilizing a standardized evaluation form with behaviorally anchored data points and comments can help with objectivity. LIC students tend to get more direct and immediate feedback, since they are working with the same preceptor over time. Students perceive this feedback as authentic and constructive because of the continuity of the preceptor [43].
The curriculum should be evaluated regularly, which allows leadership to address any gaps or unanticipated oversights that may have arisen during the implementation of the LIC. Just as a traditional curriculum measures its efficacy regularly, so should the LIC. Knowledge, skills, and attitudes of the students are all important domains to assess. Objective measures of student knowledge can be assessed and compared over time, using standardized exams, including NBME subject exams and USMLE Step 2 CK. The NBME Comprehensive Science Examination has been shown to be comparable to the individual subject examinations [44]. Students' skills are generally tracked using case logs, objective structured clinical examinations, and USMLE Step 2 CS. Students' attitudes can be measured using validated tools such as the Professional Quality of Life Scale (ProQOL 5) [45] which measures compassion satisfaction and compassion fatigue; Ethics Position Questionnaire (EPQ) [46] which measures ethical ideology along two dimensions, relativism and idealism; and the Communication, Curriculum, and Culture survey (C3) [47] which measures the professional learning climate or hidden curriculum.

Implementation of a successful LIC requires planning, buy-in from the stakeholders, and ongoing monitoring of the program to assess its effectiveness and comparability to a traditional block program. A final consideration for LIC implementation is the anticipation of situations in which a student needs to take extended time off, and how to manage when they will re-enter the curriculum. Remediating the struggling student must also be considered and incorporated into the planning. Planning for unforeseen circumstances for curriculum interruption in advance will alleviate stress when this inevitable situation arises [48].

\section{Conclusions}

The LIC model can be an extremely rewarding and beneficial way to deliver clinical experiences to medical students. It is an immersive educational experience in which students benefit from the continuity of a learning community comprised of preceptors, patients, and peers over time. Studies show that the LIC track is at least as effective as the traditional model when we measure medical knowledge and objective assessments. This model appears to promote students' independent learning and decrease ethical erosion and exposure to the "hidden curriculum," thus addressing some of the pressing concerns regarding the future of medicine.

Data Availability Not applicable.

\section{Compliance with Ethical Standards}

Conflict of Interest The authors declare that they have no conflict of interests. 
Ethics Approval Not applicable.

Consent to Participate Not applicable.

Consent for Publication Not applicable.

Code Availability Not applicable.

\section{References}

1. Halaas GW. The Rural Physician Associate Program: successful out-comes in primary care and rural practice. Rural Remote Health. 2005;5(article 453) http://www.rrh.org.au. (Accessed 30 Nov 2019).

2. Consortium of Longitudinal Integrated Clerkships (CLIC). http:// www.clicmeded.com/. [Accessed 29 Nov 2019].

3. Cooke M, Irby D, O'Brien B. Educating physicians: a call for reform of medical school and residency. Stanford: Jossey-Bass; 2010.

4. Hirsh D, Walters L, Poncelet A. Better learning, better delivery systems: possibilities from a case study of longitudinal integrated clerkships. Med Teach. 2012;34(7):548-54.

5. Mazotti L, Adams J, Peyser B, Chretien K, Duffy B, Hirsh D. Diffusion of innovation and longitudinal integrated clerkships: results of the clerkship directors in internal medicine annual survey. Med Teach. 2019;41:347-53.

6. Ford CD, Patel PG, Sierpina VS, Wolffarth MW, Rowen JL. Longitudinal continuity learning experiences and primary care career interest: outcomes from an innovative medical school curriculum. J Gen Intern Med. 2019;33:1817-21.

7. Latessa R, Beaty N, Royal K, Colvin G, Pathman D, Heck J. Academic outcomes of a community-based longitudinal integrated clerkships program. Medical Teacher. 2015;37:862-7.

8. Walters L, Greenhill J, Richards J, Ward H, Campbell N, Ash J, et al. Outcomes of longitudinal integrated clinicians and society. Med Educ. 2012;46:1028-41.

9. Hansen, Lori. Comparison of third-year student performance in a twelve-month longitudinal ambulatory program with performance in traditional clerkship curriculum. South Dakota Medicine: The Journal of the South Dakota State Medical Association. (2009-0801).

10. Schauer RW, Schieve D. Performance of medical students in a nontraditional rural clinical program 1998-99 through 2003-2004. Acad Med. 2006;81:603-7.

11. Dorsey K, Beason A, Verhulst S. Relationships matter: enhancing trainee development with a (simple) clerkship curriculum reform. Teaching and Learning in Medicine. 2019;1:76-86.

12. Melo J, Kaneshiro B, Kellett L, Hiraoka M. The impact of a longitudinal curriculum on medical student obstetrics and gynecology clinical training. Hawaii Journal of Medicine \& Public Health. 2014;73:5.

13. Hirsh D, Gaufberg E, Ogur B, Cohen P, Krupat E, Cox M, et al. Educational outcomes of the Harvard Medical School-Cambridge integrated clerkship: a way forward for medical education. Acad Med. 2012;87(5):643-50.

14. Walters L, Worley P, Greenhill J. Demonstrating the value of longitudinal integrated placements for general practice preceptors. Med Educ. 2011;45:455-63.

15. Cuncic C, Regehr G, Frost H, Bates J. It's all about relationships. Perspectives on Medical Education. 2018;7:100-9.

16. Snow S, Gong J, Adams J. Faculty experience and engagement in a longitudinal integrated clerkship. Medical Teacher. 2017;39:52734.
17. Poncelet A, Bokser S, Calton B, Hauer K, Kirsch H, Jones T, et al. Development of a longitudinal integrated clerkship at an academic medical center. Med Educ Online. 2011;16:1. https://doi.org/10. 3402/meo.v16i0.5939.

18. Caygill R, Peardon M, Waite C, Wright J. Comparing a longitudinal integrated clerkship with traditional hospital-based rotations in a rural setting. Medical Teacher. 2017;39:520-6.

19. Birden H, Barker J, Wilson I. Effectiveness of a rural longitudinal integrated clerkship in preparing medical students for internship. Medical Teacher. 2016;38:946-56.

20. Gaufberg E, Hirsh D, Krupat E, Ogur B, Pelletier S, Reiff D, et al. Into the future: patient centredness endures in longitudinal integrated clerkship graduates. Med Educ. 2014;48:572-82.

21. Frattarelli LC, Kamemoto LE. Obstetrics and gynecology medical student outcomes: longitudinal multispecialty clerkship versus traditional block rotations. Am J Obstet Gynecol. 2004;191(5):1800 4.

22. Poncelet A, Walmsley M, Hauer K, Lai C, Becker T, O'Brien B. Patient views of continuity relationships with medical students. Medical Teacher. 2013;35:465-71.

23. Hudson JN, Knight PJ, Weston KM. Patient perceptions of innovative longitudinal integrated clerkships based in regional, rural and remote primary care: a qualitative study. BMC Fam Pract. 2012;13: 72 .

24. Greenhill J, Fielke K, Richards J, Walker L, Walters L. Towards an understanding of medical student resilience in longitudinal integrated clerkships. BMC Medical Education. 2015;15:137.

25. Dube T, Schinke R, Strasser R, Couper I, Lightfoot N. Transition processes through a longitudinal integrated clerkship: a qualitative study of medical student experiences. Med Educ. 2015;49:102837.

26. Konkin D, Suddards C. Who should choose a rural LIC: a qualitative study of perceptions of students who have completed a rural longitudinal integrated clerkship. Medical Teacher. 2015;37(2): 1026-31.

27. Ellaway R, Graves L, Berry S, Myhre D, Cummings B, Konkin J. Twelve tips for designing and running longitudinal integrated clerkships. Med Teach. 2013;35:989-95.

28. Foster JH, Byerley J, Tarantino H, Chuang A, Pino J, Latessa R, et al. Cracking the nut on LCME Standard 8.7: innovations to ensure comparability across geographically distributed campuses. Teaching and Learning in Medicine. 2019.

29. Bing-You RG, Trowbridge R, Kruithoff C. Unfreezing the Flexnerian model: introducing longitudinal integrated clerkships in rural communities. Rural Remote Health. 2014;14:2944.

30. Bernstein J, Mazotti L, Ziv TA, et al. Texting brief podcasts to deliver faculty development to community- based preceptors in longitudinal integrated clerkships. MedEdPORTAL. 2018;14: 10755. https://doi.org/10.15766/mep_2374-8265.10755.

31. Bernstein J, Wood S, Latessa R, Hirsh D. Teaching in longitudinal integrated clerkships: the seven C's. Clinical Teacher. 2018;16: $101-7$.

32. Latessa R, Schmitt A, Beaty N, Bule S, Ray L. Preceptor teaching tips in longitudinal clerkships. Clinical Teacher. 2016;133:213-8.

33. Teherani A, O'Brien B, Masters D, Poncelet A, Robertson P, Hauer K. Burden, responsibility, and reward: preceptor experiences with the continuity of teaching in a longitudinal Integrated clerkship. Academic Medicine. 2009;84:S50-3.

34. Hudson JN, Weston KM, Farmer EA. Medical students on longterm regional and rural placements: what is the financial cost to supervisors? Rural Remote Health. 2012;12(2):1951.

35. Connolly M, Sweet L, Campbell D. What is the impact of longitudinal rural medical student clerkships on clinical supervisors and hospitals? Australian Consortium of Longitudinal Integrated Clerkships (CLIC). http://www.clicmeded.com/. [Accessed 29 Nov 2019.] 
36. Shahi R, Walters L, Ward H, Woodman R, Prideaux D. Clinical participation of medical students in three contemporary training models. Med Educ. 2015;49:1219-28.

37. Worley P, Couper I, Strasser R, Graves L, Cummings B, Woodman $\mathrm{R}$, et al. A typology of longitudinal integrated clerkships. Med Educ. 2016;50:922-32.

38. Heddle W, Robertson G, Mahoney S, Walters L, Strasser S, Worley P. Challenges in transformation of the "traditional block rotation" medical student clinical education into a longitudinal clerkship model. Education for Health. 2014;27:138-42.

39. Alphonso A, Pathy S, Bruno C, Emerson B, Crabtree J, Johnston L, et al. Shoulder dystocia and neonatal resuscitation: an integrated obstetrics and neonatology simulation for medical students. MedEdPORTAL. 2017;13:10594. https://doi.org/10.15766/mep_ 2374-8265.10594.

40. Mazotti L, O’Brien B, Tong L, Hauer KE. Perceptions of evaluation in longitudinal versus traditional clerkships. Med Educ. 2011;45: 464-70.

41. Alegria D, Boscardin C, Poncelet A, Mayfield C, Wamsley M. Using tablets to support self-regulated learning in a longitudinal integrated clerkship. Medical Education Online. 2014;19:23638.

42. Association of Professor in Obstetrics and Gynecology (APGO). https://www.apgo.org/educational-resources/apgo-medicalstudent-educational-objectives/ [Member only access, Jul 2020].
43. Bates J, Konkin J, Suddards C, Dobson S, Pratt D. Student perceptions of assessment and feedback in longitudinal integrated clerkships. Med Educ. 2013;47:362-74.

44. Peterson L, Rusticus S, Ross L. Comparability of the national board of medical examiners comprehensive clinical science examination and a set of five clinical science subject examinations. Acad Med. 2015;90(5):684-90.

45. Figley C. Treating compassion fatigue. Brunner-Rutledge: London; 2002.

46. Forsyth DR. A taxonomy of ethical ideologies. J Pers Soc Psychol. 1980;39:175-84.

47. Haidet P, Kelly PA, Chou C. Characterizing the patientcenteredness of hidden curricula in medical schools: development and validation of a new measure. Acad Med. 2005;80(1):44-50.

48. Poncelet AN, Mazotti LA, Blumberg B, Wamsley MA, Grennan T, Shore WB. Creating a longitudinal integrated clerkship with mutual benefits for an academic medical center and a community health system. Perm J. 2014;18(2):50-6. https://doi.org/10.7812/TPP/13137.

Publisher's Note Springer Nature remains neutral with regard to jurisdictional claims in published maps and institutional affiliations. 